\title{
Incidence and clinical feature of Myasthenia gravis: A five- year data analysis in Ulaanbaatar, Mongolia
}

Oyunaa Chimedregzen ${ }^{1}$, Sarangerel Jambal ${ }^{2}$, Munkhbayar Rentsenbat ${ }^{2}$ and

Byambasuren Dagvajantsan ${ }^{1, *}$

${ }^{1}$ Department of Neurology, School of Medicine, Mongolian National University of Medical Sciences, Ulaanbaatar, Mongolia.

${ }^{2}$ Reflex neurology hospital, Ulaanbaatar, Mongolia.

* Correspondence: byambasuren@mnums.edu.mn; Tel.: +976-99011455

Received: 4 July 2021; Accepted: 25 October 2021; Published: 30 November 2021

Edited by: Battuvshin Lkhagvasuren (Mongolian National University of Medical Sciences, Mongolia)

Reviewed by: Tuvshingerel Sandagdorj (National Cancer Center of Mongolia, Mongolia);

Goh Khean Jin (Universiti Malaya, Malaysia)

https://doi.org/10.31117/neuroscirn.v4i3Suppl.96

\begin{abstract}
Myasthenia gravis (MG) is a rare neuromuscular disorder. Till now, there are no studies on the prevalence and incidence of MG in Mongolia. The current study aimed to elucidate the incidence of MG in Ulaanbaatar, the age of onset, and the gender distribution of Mongolian patients with MG. We conducted a cross-sectional, hospital-based study involving MG patients $(n=48)$ all around Ulaanbaatar from 1 January 2015 to 1 January 2020. The clinical diagnosis was assessed with the Myasthenia Gravis Foundation of America (MGFA) classification system. The disease severity was evaluated by using Osserman's classification. The diagnosis was confirmed with serological and electrophysiological tests. Statistical analysis was performed using SPSS software. A total of 30 patients with MG were registered for the last five years in Ulaanbaatar. The average annual incidence of MG in Ulaanbaatar was 0.65 per 100,000 populations $(95 \% \mathrm{Cl}$ $0.26-1.34), 0.60$ in males $(95 \% \mathrm{Cl} 0.25-1.28)$, and 0.69 in females $(95 \% \mathrm{Cl} 0.33-1.46)$. The cumulative incidence in the study period was 3.2 per 100,000 populations. The ratio of males to females was $1: 1,3$. The median age for onset of MG was 33 years (ranging from 27 to 46 years); $43.3 \%$ of patients had ocular and $56.7 \%$ generalized symptoms at the disease onset. Only $23.3 \%$ of patients remained with purely ocular symptoms (Osserman I stage). The average incidence of MG between 2015 and 2020 was 6,5 per 1.000 .000 population, and the annual incidence was relatively stable. Although ocular and generalized symptoms were observed each in about half of the cases, only one-fourth remained with pure ocular signs at the end of the review period.
\end{abstract}

Keywords: Myasthenia gravis; annual incidence; early-onset myasthenia gravis; late-onset myasthenia gravis;

C2021 by Chimedregzen et al. for use and distribution according to the Creative Commons Attribution (CC BY-NC 4.0) license (https://creativecommons.org/licenses/by-nc/4.0/), which permits unrestricted non-commercial use, distribution, and reproduction in any medium, provided the original author and source are credited

\subsection{INTRODUCTION}

Myasthenia gravis (MG) is an autoimmune antibodymediated chronic disorder affecting the postsynaptic membrane of neuromuscular junctions (Gilhus et al., 2015; Pakzad et al., 2011). MG is characterized by fluctuating weakness and fatigability of voluntary muscles improving with rest and worsening with repetitive usage (Turner, 2007; Vincent, 2008). According to a survey of MG cases worldwide over the past 60 years, the incidence rate ranged from 1.7 to 21.3 cases per million person-years, and the prevalence rate ranged from 15-179 per million (Carr et al., 2010). 
Studies demonstrating age and gender show that it is more common in young (20-40) women and older (5070) men, and females are more commonly affected than males (about 1:1.5) (Aarli, 1999; Carr et al., 2010; Lee et al., 2018). Alshekhlee and colleagues studied a hospitalbased study of 5,502 patients in the United States from 2000 to 2005 and found that the incidence was 2-3 times higher in women during the first five decades. In men, the incidence of admission was higher during the sixth, seventh, and eighth decades (Alshekhlee et al., 2009). In comparison, the incidence of MG has been steadily rising in Asian countries for the past 30 years (Leeamornsiri et al., 2011; Murai et al., 2011). Japanese colleagues reported about decreasing incidence of early-onset Myasthenia gravis (EOMG) in 2005 compared with 1987, while the incidence of late-onset Myasthenia gravis (LOMG) was increased (Murai et al., 2011).

According to the Myasthenia Gravis Foundation of America (MGFA) classification, MG is clinically classified as an ocular and generalized form (mild, moderate, severe, and intubation needed to maintain the airway) (Jaretzki et al., 2000). The ocular symptoms are frequently the first manifestation signs of MG (Ding et al., 2020), tending to spread to the other parts of the body within two years of disease onset (Bever Jr et al., 1983). MG produces long-term disability and affects health-related quality of life. Patients with MG get disability approval from specialists in our country when the serological and electrophysiological tests are positive. The duration of disability benefits will be decided based on the clinical manifestations of the MG in Mongolia.

There are no studies known for this neuromuscular disease in Mongolia. According to an annual report from the National Statistical Office of Mongolia, neuromuscular diseases were not registered constantly and were often referred to as the classification of other diseases. No data are available on the MG prevalence and incidence in Mongolia, and there are also no guidelines for the diagnosis and treatment of MG.

Almost half of Mongolia's three million population lives in the capital city of Mongolia. The serological and electrophysiological diagnostic can confirm the diagnosis of MG but are available only in the capital city. Therefore, confirming the diagnosis of MG in rural areas is not available. The current study aims to elucidate the incidence of the MG in Ulaanbaatar city and analyze the age of disease onset, gender distribution, and clinical symptoms of patients with MG.

\subsection{MATERIALS AND METHODS}

The Ulaanbaatar city is officially divided into nine districts: Baganuur, Bagakhangai, Bayangol, Bayanzurkh, Chingeltei, Sukhbaatar, Songinokhairkhan, Khan-Uul and Nalaikh. The patients with suspected MG are first referred to a district neurologist for diagnostic and follow-up care. The data of all patients with MG (G70.0) attending the nine district hospitals as outpatient visits or in hospital admission data were collected in this study. In addition, the patients were selected based on a serological and electrophysiological test of MG, which was available only in two hospitals in Ulaanbaatar, Mongolia (The Reflex Neurological Clinic, and the Japan-Mongolia Teaching Hospital). Twentyfour patients from nine districts hospital, 42 patients from Reflex Neurological hospitals, and ten patients from Japan-Mongolia teaching hospitals were overlapped registered with a diagnosis of MG.

We conducted a cross-sectional, hospital-based study involving MG patients ( $n=48$ ) diagnosed clinically and by serological and electrophysiological tests in Ulaanbaatar city from 1 January 2015 to 1 January 2020. The study inclusion criteria were: 1) citizenship of Ulaanbaatar city; 2 ) the clinical diagnosis of MG was confirmed by at least 1 serological or electrophysiological test. The exclusion criteria include living in rural areas, a childhood MG or Lambert-Eaton myasthenic syndrome. The clinical manifestation at the beginning of the MG is not specific for MG, leading to misdiagnosis or delayed diagnosis. This study only confirmed the diagnosis using the serological and electrophysiological test to prevent the misdiagnosis. There is no availability to confirm the diagnosis of MG in the rural areas due to a lack of diagnostic tools capacity. We only included the patients from Ulaanbaatar city to improve the accuracy of the study. We aimed to study the incidence of MG among adults in Mongolia, so patients below 18 years are excluded from this study. Lambert-Eaton myasthenic syndrome is similar to $M G$ in terms of clinical manifestation, which could be misdiagnosed as MG. According to exclusion criteria, 18 people with MG were excluded, and the remaining 30 were identified for the review. The study was conducted accordingly to the Helsinki Declaration, and it was approved by the Medical Ethical Committee of the Mongolian National University of Medical Sciences (METc №2020/3-04).

We used the registration data of the total population of Ulaanbaatar in 2015-2020 by gender from The Ulaanbaatar Statistics Office (www.ubstat.mn), estimated the number of people over 18 years of age, and then calculated the average number of adults in the 
last 5 years (Table 1). We divided the MG patients into the following two groups depending on the age of onset: 1) early-onset myasthenia gravis (EOMG) with age under 45 and 2) late-onset myasthenia gravis (LOMG) with age over 45 years. In addition, the population data from the Ulaanbaatar statistics office between 2015 and 2020 were obtained and calculated the age-adjusted incidence rate by weighing the absolute numbers with the population of the corresponding age group (aged $>45$ and $<45$ years old) (Table 2).

Table 1: Gender-specific annual population in Ulaanbaatar.

\begin{tabular}{lcccccc}
\hline \multirow{2}{*}{ Year } & \multicolumn{2}{c}{ Total } & \multicolumn{2}{c}{ Female } & \multicolumn{2}{c}{ Male } \\
\cline { 2 - 7 } & Population & $\mathbf{> 1 8}$ years & Population & $\mathbf{> 1 8}$ years & Population & >18 years \\
\hline 2015 & $1,345,500$ & 892,942 & 694,521 & 473,182 & 650,979 & 419,760 \\
2016 & $1,380,792$ & 921,857 & 718,892 & 493,775 & 661,900 & 428,082 \\
2017 & $1,417,396$ & 941,517 & 737,838 & 503,721 & 679,558 & 437,796 \\
2018 & $1,394,363$ & 941,198 & 721,420 & 500,112 & 672,943 & 441,086 \\
2019 & $1,466,125$ & 938,505 & 755,670 & 498,024 & 710,455 & 440,481 \\
Average & $\mathbf{1 , 4 0 0 , 8 3 5}$ & $\mathbf{9 2 7 , 2 0 3}$ & $\mathbf{7 2 5 , 6 6 8}$ & $\mathbf{4 9 3 , 7 6 3}$ & $\mathbf{6 7 5 , 1 6 7}$ & $\mathbf{4 3 3 , 4 4 1}$ \\
\hline
\end{tabular}

Table 2: Age-specific annual adult population in Ulaanbaatar.

\begin{tabular}{lcccc}
\hline Year & Total Population & $>\mathbf{1 8}$ years & EOMG (<45 years) & LOMG (>45 years) \\
\hline 2015 & $1,345,500$ & 892,942 & 635,388 & 257,554 \\
2016 & $1,380,792$ & 921,857 & 652,375 & 269,482 \\
2017 & $1,417,396$ & 941,517 & 658,819 & 282,698 \\
2018 & $1,394,363$ & 941,198 & 645,830 & 295,368 \\
2019 & $1,466,125$ & 938,505 & 629,223 & 309,282 \\
Average & $\mathbf{1 , 4 0 0 , 8 3 5}$ & $\mathbf{9 2 7 , 2 0 3}$ & $\mathbf{6 4 4 , 3 2 7}$ & $\mathbf{2 8 2 , 8 7 6}$ \\
\hline
\end{tabular}

We followed the Myasthenia Gravis Foundation of America (MGFA) Clinical Classification to assess the clinical manifestation at the onset of the disease (Table 3) (Jaretzki et al., 2000) and also used Osserman's classification for evaluating the severity of the disease (Table 4). The statistical analysis was performed using SPSS version 27.0 software. Continuous variables were presented as means with standard deviations (SD), and median values were reported for variables with nonparametric distributions, whereas categorical variables were reported as numbers with proportions. The Mid-P exact test was used to estimate the incidence of MG. A two-sided statistical significance was set at $p<0.05$ for all tests.

Table 3: Myasthenia Gravis Foundation of America (MGFA) clinical classification.

\begin{tabular}{cl}
\hline Grade & Clinical symptoms \\
\hline I & Ocular MG \\
Ila & Mild generalized MG, predominant limb or axial muscles involvement \\
IIIa & Mild generalized MG, predominant bulbar or respiratory muscles involvement \\
IIIb & Moderate generalized MG, predominant limb or axial muscles involvement \\
IVa & Severe generalized MG, predominant limb or axial muscles involvement \\
IVb & Severe generalized MG, predominant bulbar or respiratory muscles involvement \\
V & MG cases requiring intubation \\
\hline
\end{tabular}


Table 4: Osserman's grading (maximum disease severity).

\begin{tabular}{cl}
\hline Stage & Clinical symptoms \\
\hline I & $\begin{array}{l}\text { Ocular myasthenia gravis: involvement of extraocular muscle with diplopia and ptosis } \\
\text { Mild generalized myasthenia gravis: ocular symptoms are associated with slow involvement of bulbar } \\
\text { (dysphagia and dysarthria) and skeletal muscles (generalized weakness). Respiratory muscles are } \\
\text { spared. }\end{array}$ \\
IIb & $\begin{array}{l}\text { Moderately generalized myasthenia gravis: progressive onset of symptoms with significant } \\
\text { manifestation of weakness. Respiratory muscles are spared. }\end{array}$ \\
III & $\begin{array}{l}\text { Acute myasthenia gravis: rapid onset (within } 6 \text { months) of severe bulbar and skeletal muscles } \\
\text { involvement with important weakness. Respiratory muscles are involved. } \\
\text { IV }\end{array}$ \\
\hline
\end{tabular}

\subsection{RESULTS}

We reviewed a total of 30 patients' medical records with confirmed MG in Ulaanbaatar from 2015 to 2020.

\subsection{Incidence}

The average annual incidence of MG in Ulaanbaatar was 0.65 per 100,000 populations $(0.26-1.34$ with $95 \% \mathrm{Cl}$ (Confidence Interval)), 0.60 for males (0.25-1.28 with $95 \% \mathrm{Cl})$, and 0.69 for females $(0.33-1.46$ with $95 \% \mathrm{Cl})$. The annual incidence was relatively stable (Table 5). The cumulative incidence was $3.2(2.22-4.56$ with $95 \% \mathrm{Cl})$ per 100,000 populations. The average annual incidence of EOMG was 0.56 per 100,000 populations (0.25-1.12 with $95 \% \mathrm{Cl}$ ) and for LOMG was 0.84 per 100,000 populations (0.39-1.97 with $95 \% \mathrm{Cl}$ ) (Table 6). Surveyed by area of the residence, there were 7 cases from Bayanzurkh district, 6 cases from Khan-Uul district, 5 cases from Chingeltei district, 4 cases from Sukhbaatar district, 4 cases from Songinokhairkhan district, 3 cases from Bayangol district, and 1 case from Baganuur district. However, no cases were reported from Nalaikh and Bagakhangai districts in those years. The number of cases was calculated per 100,000 population due to the different population numbers in each district. The highest number of cases was reported in Khan-Uul district (5.53 per 100,000), and the lowest number of cases was reported in Songinokhairkhan district (1.92 per 100,000). The number of cases for the remaining districts was counted as follows: Baganuur district (5.23 per 100,000), Chingeltei district (4.82 per 100,000), Sukhbaatar district $(4.27$ per 100,000$)$, Bayanzurkh district (3.14 per 100,000), and Bayangol district (2.07 per 100,000).

\subsection{Age and sex distribution}

The median age at onset was 33 years (interquartile range 27-46 years), and the mean age at onset was $37.27 \pm 13.83$ years (19-72 years). Among all probands, $43.3 \%(n=13)$ were male, and $56.7 \%(n=17)$ were female. The gender ratio of males to females was 1: 1,3. The peak age of MG in both genders was 31-40 years (Figure 1). Assessing the relationship between incidence and age group, the number of cases of LOMG has decreased in the last two years, while the number of cases of EOMG has increased rapidly (Figure 2).

Table 5: Gender-specific annual incidence (per 100,000 persons) of Myasthenia gravis with intervals among adults in Ulaanbaatar.

\begin{tabular}{lcccccc}
\hline \multirow{2}{*}{ Year } & \multicolumn{3}{c}{ Total } & Female & Male \\
\cline { 2 - 7 } & $\mathbf{N}^{*}$ & Incidence $\left(\mathbf{C I}^{* *}\right)$ & $\mathbf{N}^{*}$ & Incidence $\left(\mathbf{C I}^{* *}\right)$ & $\mathbf{N}^{*}$ & Incidence $\left(\mathbf{C l}^{* *}\right)$ \\
\hline 2015 & 3 & $0.33(0.09-0.91)$ & 2 & $0.42(0.07-1.40)$ & 1 & $0.24(0.01-1.17)$ \\
2016 & 7 & $0.76(0.33-1.50)$ & 3 & $0.61(0.15-1.65)$ & 4 & $0.93(0.30-2.25)$ \\
2017 & 6 & $0.64(0.26-1.32)$ & 4 & $0.79(0.25-1.92)$ & 2 & $0.46(0.07-1.51)$ \\
2018 & 7 & $0.74(0.33-1.47)$ & 5 & $0.99(0.37-2.22)$ & 2 & $0.45(0.07-1.5)$ \\
2019 & 7 & $0.75(0.33-1.37)$ & 3 & $0.60(0.15-1.64)$ & 3 & $0.45(0.08-1.50)$ \\
Average & $\mathbf{6}$ & $\mathbf{0 . 6 5 ( 0 . 2 6 - 1 . 3 4 )}$ & $\mathbf{3 . 4}$ & $\mathbf{0 . 6 9 ( 0 . 3 3 - 1 . 4 6 )}$ & $\mathbf{2 . 6}$ & $\mathbf{0 . 6 0 ( 0 . 2 5 - 1 . 2 8 )}$ \\
\hline
\end{tabular}

$\mathrm{N}^{*}$-Number of new cases; $\mathrm{Cl}^{* *}-95 \%$ Confidence Interval 
Table 6. Age-specific annual incidence (per 100,000 persons) of Myasthenia gravis with intervals among adults in Ulaanbaatar.

\begin{tabular}{|c|c|c|c|c|c|c|}
\hline \multirow{2}{*}{ Year } & \multicolumn{2}{|r|}{ Total } & \multicolumn{2}{|r|}{ EOMG } & \multicolumn{2}{|c|}{ LOMG } \\
\hline & $\mathbf{N}^{*}$ & Incidence $\left(\mathrm{Cl}^{* *}\right)$ & $\mathbf{N}^{*}$ & Incidence $\left(\mathrm{Cl}^{* *}\right)$ & $\mathbf{N}^{*}$ & Incidence $\left(\mathrm{Cl}^{* *}\right)$ \\
\hline 2015 & 3 & $0.33(0.09-0.91)$ & 3 & $0.47(0.12-1.29)$ & 4 & $0.16(0.12-1.29)$ \\
\hline 2016 & 7 & $0.76(0.33-1.50)$ & 3 & $0.46(0.12-1.25)$ & 4 & $0.15(0.05-0.39)$ \\
\hline 2017 & 6 & $0.64(0.26-1.32)$ & 2 & $0.46(0.12-1.24)$ & 3 & $0.11(0.03-0.29)$ \\
\hline 2018 & 7 & $0.74(0.33-1.47)$ & 4 & $0.62(0.20-1.49)$ & 1 & $0.34(0.07-1.5)$ \\
\hline 2019 & 7 & $0.75(0.33-1.37)$ & 6 & $0.95(0.39-2.12)$ & - & - \\
\hline Average & 6 & $0.65(0.26-1.34)$ & 3.6 & $0.56(0.25-1.12)$ & 2.4 & $0.84(0.39-1.97)$ \\
\hline
\end{tabular}

EOMG ( $\leq 45$ years); LOMG (>45 years); $\mathrm{N}^{*}$-Number of new cases; Cl**-95\% Confidence Interval

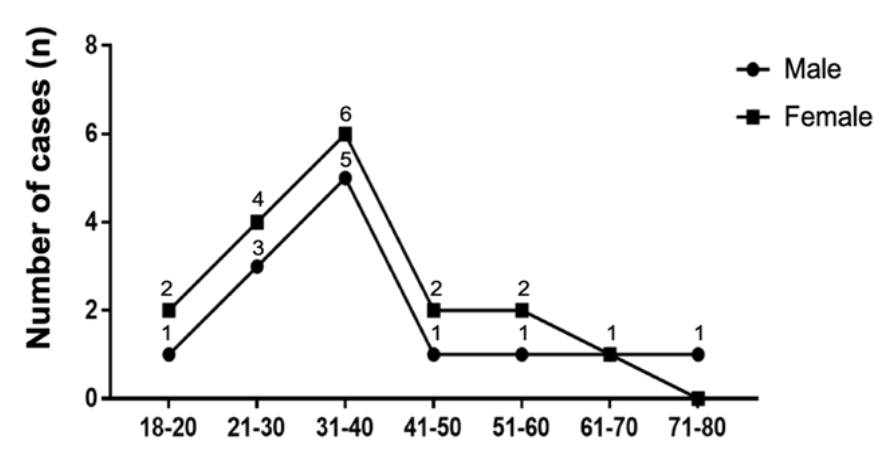

Age of onset (year)

Figure 1: Age group at onset of disease in 2015-2020. The peak age was from 31 to 40 years in both genders.

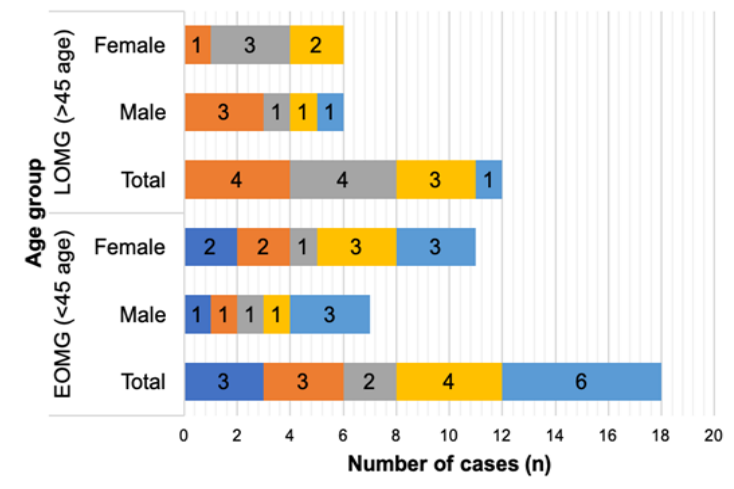

- 2015-2016 $=2016-2017$ $=2017-2018$ $=2018-2019$ $=2019-2020$

Figure 2: Annual number of cases of MG in 2015-2020 in Ulaanbaatar (by age group).

\subsection{Clinical features of MG in Ulaanbaatar}

The initial presenting symptoms were classified into seven categories: ocular symptoms, bulbar symptoms, lower extremity weakness, upper extremity weakness, facial weakness, neck flexor weakness, and respiratory failure. The most common initial presenting symptoms were ocular and bulbar symptoms in $56.6 \%(n=17)$ and $40.0 \%(n=12)$ of patients, respectively. Besides, $20.0 \%$ $(n=6)$ of patients presented with lower extremity weakness, $13.3 \%(n=4)$ with upper extremity weakness, $10.0 \%(n=3)$ with facial weakness, $3.3 \%(n=1)$ of patients had neck flexors weakness, and no one showed respiratory failure. Figure $\mathbf{3}$ shows the frequency of initial presenting symptoms as reported by the patients with MG. The clinical manifestation at the onset of the disease was assessed according to the MGFA classification. At the onset of the MG $43.3 \%$ and $56.7 \%$ were ocular and generalized MG forms, respectively (Figure 4). Among the patients with generalized MG $36.7 \%(n=11)$ of patients were classified with grade II, $20 \%(n=6)$ with grade III. No patients have presented with grade IV or V. $46.2 \%$ of patients with initial ocular presentation shifted to generalized symptoms. The average period of shifting ocular to generalized symptoms was 23 months (1-140 months). The maximum disease severity was evaluated using Osserman's classification. At the end of the review period, only $23.3 \%$ of patients remained with purely ocular symptoms (stage I). In comparison, $76.7 \%$ of patients continued to have generalized MG, among them $43.3 \%$ with Osserman stage Ila, $20 \%$ with stage IIb, $6.7 \%$ with stage III and $6.7 \%$ with stage IV (Figure 5).

\subsection{DISCUSSION}

Our study is the first study of the incidence of MG in Ulaanbaatar (Mongolia). Myasthenia gravis is well investigated in other countries. Spain has the highest annual incidence among European countries in the last 10 years (2.1 per 100,000), while Norway (0.04 per 100,000 ) has the lowest number of cases (Boldingh et al., 2015). Among Asian countries, the annual incidence rate was similar in Japan $(0.69-0.87$ per 100,000$)$, Korea (0.69 per 100,000), and China $(0.68$ per 100,000$)$ (Chen et al., 2020; Lee et al., 2016; Matsui et al., 2009) Our estimated average annual incidence rate during the period 2015-2020 among the population in Ulaanbaatar 
(0.65 per 100,000) had no significant difference compared to other Asian countries.

Several studies have shown that the incidence of the disease tends to increase every year due to improved MG diagnostic capacity (Casetta et al., 2010; Matsuda et al., 2005). In our study, the annual incidence was relatively stable, although we found that the incidence of EOMG has increased, and the incidence of LOMG has slightly decreased in the last two years. The decrease in the number of LOMG may be explained by a lack of correct diagnostic of muscle weakness due to confusing clinical interpretation in the elderly. If we look to the age-adjusted incidence of MG was approximately 2.5-3 times higher in the younger $(\leq 45)$ compared with, the older (>45) age group.

Although the MG can affect people of all ages, there is a bimodal distribution of onset age for females and males. In the female population, Wing et al. (2003) observed two peaks between $40-49$ years and 60-69 years. Lavrnić et al. (1999) reported about two peaks between 20-40 years and 70-80 years. However, Mantegazza et al. (2003) and Singhal et al. (2008) reported a single peak in the females in the third decade. In the male patients, Mantegazza et al. (2003) observed a bimodal onset with peaks in the third and sixth decade. However, Singhal et al. (2008) and Poulas et al. (2001) reported single peaks in the sixth to a seventh decade in males. In our study, the onset of MG was observed at a single peak (31-40 years) in males and females, which can depend on the pure diagnostic capacity in elderly patients in our country. Most studies in Europe have shown that MG is predominant in females. For example, the MG male to female gender ratio was 1:1.41 in Greece (Poulas et al., 2001) and 1:1.94 in Italy (Mantegazza et al., 2003). Studies in most Asian countries showed that MG was predominant in females: Singapore 1:1,6, Hong Kong 1:2,1 (Wing et al., 2003; Yu et al., 1992). On the contrary, a study from India showed MG predominancy in males (Singhal et al., 2008). Our study showed a female preponderance among the people with MG, corroborating the outcome of other studies.

As in most studies, we observed ocular and bulbar signs as the most common initial presenting symptoms. However, compared with studies in Singapore and Nigeria, ocular symptoms were less pronounced, while bulbar symptoms were more pronounced (Wing et al., 2003; Oparah \& Ibanga, 2020).

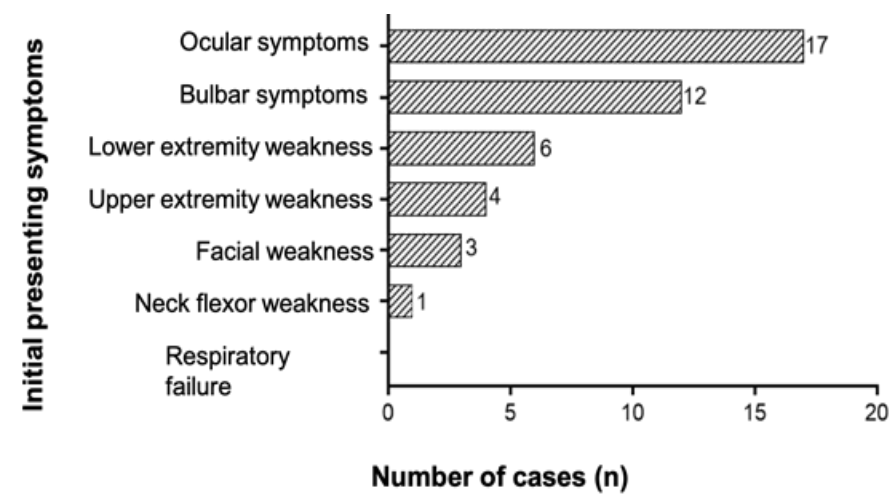

Figure 3: Initial presenting symptoms of Myasthenia gravis.

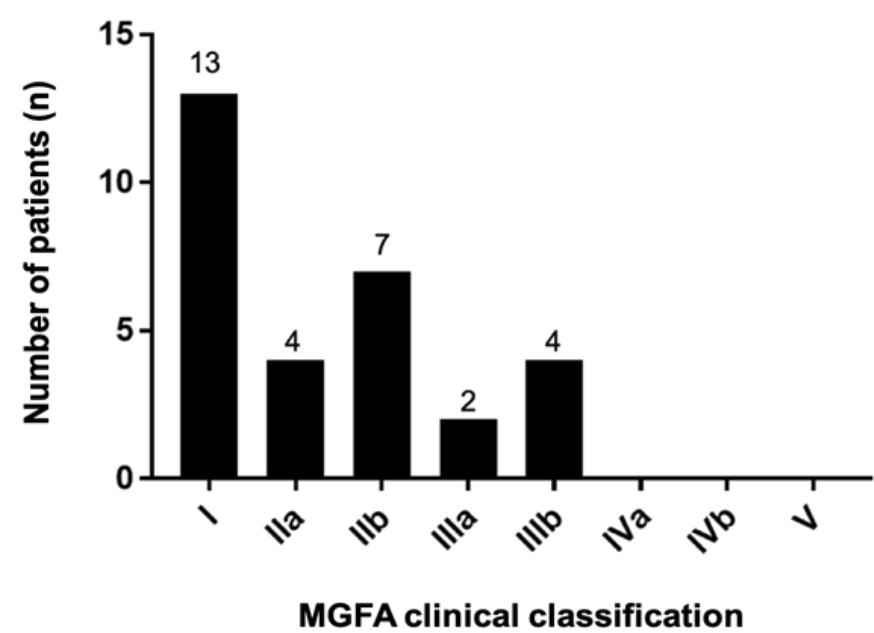

Figure 4: MGFA clinical classification of myasthenia gravis at the onset of disease.

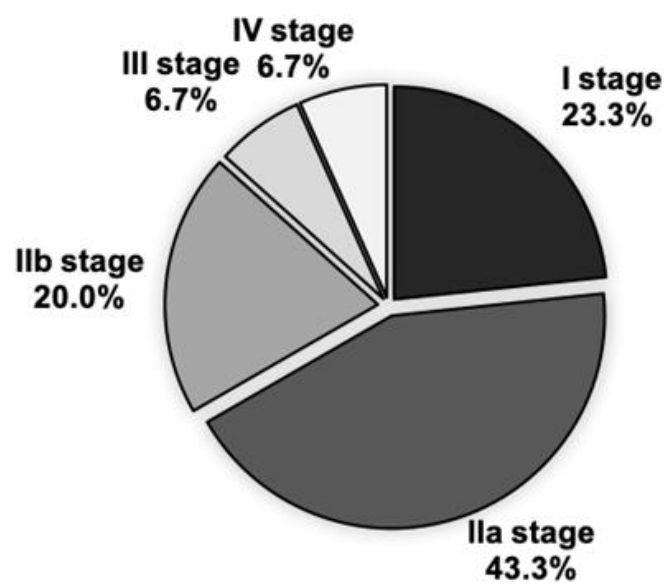

Figure 5: Osserman's classification of maximum disease severity. 
The classification of MGFA described in studies reported by Asian countries has been determined that the ocular MG (MGFA I grade) rate was 26.3\% (India), 32.7\% (Hong Kong), and 55\% (Singapore) (Wing et al., 2003; Singhal et al., 2008; Yu et al., 1992). Ocular signs as the initial symptoms of MG occurred in Mongolia more often $(43.3 \%)$ than in India or Hong Kong. Respiratory failure can be a severe presenting feature of myasthenia gravis. In the studies reported by Mantegazza et al. (2003); Singhal et al. (2008) $0.8 \%$ and $1.32 \%$ presented with respiratory symptoms. No one in our study was presented with respiratory failure.

At the end of the survey, only one-fourth of patients remained with purely ocular symptoms, and the rest progressed to the generalized MG. The average duration of disease progression was 23 months (1-140 months). Robertson's study reported, $10-20 \%$ of the MG tend to be pure ocular $M G$, and the remaining of the myasthenia gravis will turn into generalized MG in two years (Kupersmith et al., 2003).

We conducted the first study of MG in Mongolia, defining the incidence and the clinical features of the disease in our country. The data of this study can be used as primary research data of this disease in the future and will encourage the caregivers the improve MG diagnostic possibilities. This study was limited to only citizens of Ulaanbaatar. In future, we need to extend our study including patients from the rural areas of the country, more differentiated serological data, and treatment results.

\subsection{CONCLUSIONS}

The average incidence of MG between 2015 and 2020 was 6 per 1.000 .000 population. The annual incidence was relatively stable. Myasthenia gravis in our study was more common in females ( $\mathrm{M}: \mathrm{F}$ of 1:1.3).

Acknowledgements: The authors acknowledge and thank the study team and the Mongolian National University of Medical Sciences for their support, as well as all the study participants. We also thank an anonymous reviewer for their excellent critique of the manuscript and for helping us better our work.

Author Contributions: B.D, O.Ch, S.J, and MR conceived and designed the study; O.Ch and MR collected data; O.Ch and BD analyzed the data; BD and O.Ch wrote the paper; SJ and BD reviewed and edited the paper.

Conflicts of Interest: The authors declare no conflict of interest.

\section{References}

Aarli J.A. (1999). Late-onset myasthenia gravis: a changing scene. Archives of Neurology, 56(1), 25-27. https://doi.org/10.1001/ARCHNEUR.56.1.25

Alshekhlee, A., Miles, J. D., Katirji, B., Preston, D. C., \& Kaminski, H. J. (2009). Incidence and mortality rates of myasthenia gravis and myasthenic crisis in US hospitals. Neurology, 72(18), 1548-1554. https://doi.org/10.1212/WNL.0B013E3181A41211

Bever Jr, C. T., Aquino, A. V., Penn, A. S., Lovelace, R. E., \& Rowland, L. P. (1983). Prognosis of ocular Myasthenia. Annals of Neurology, 14(5), 516-519. https://doi.org/10.1002/ANA.410140504

Boldingh, M. I., Maniaol, A. H., Brunborg, C., Dekker, L., Heldal, A. T., Lipka, A. F., Popperud, T. H., Niks, E. H., Verschuuren, J. J. G. M., \& Tallaksen, C. M. E. (2015). Geographical distribution of myasthenia gravis in northern europe - results from a population-based study from two countries. Neuroepidemiology, 44(4), 221-231. https://doi.org/10.1159/000431036

Carr, A. S., Cardwell, C. R., McCarron, P. O., \& McConville, J. (2010). A systematic review of population based epidemiological studies in Myasthenia Gravis. BMC Neurology, 10. https://doi.org/10.1186/1471-2377-10-46

Casetta, I., Groppo, E., De Gennaro, R., Cesnik, E., Piccolo, L., Volpato, S., \& Granieri, E. (2010). Myasthenia gravis: a changing pattern of incidence. Journal of Neurology, 257(12), 2015-2019. https://doi.org/10.1007/S00415-010-5651-Z

Chen, J., Tian, D. C., Zhang, C., Li, Z., Zhai, Y., Xiu, Y., Gu, H., Li, H., Wang, Y., \& Shi, F. D. (2020). Incidence, mortality, and economic burden of myasthenia gravis in China: A nationwide population-based study. The Lancet Regional Health. Western Pacific, 5, 100063. https://doi.org/10.1016/J.LANWPC.2020.100063

Ding, J., Zhao, S., Ren, K., Dang, D., Li, H., Wu, F., Zhang, M., Li, Z., \& Guo, J. (2020). Prediction of generalization of ocular myasthenia gravis under immunosuppressive therapy in Northwest China. BMC Neurology, 20(1), 1-8. https://doi.org/10.1186/S12883-020-01805-1

Gilhus N.E., Nacu A., Andersen J.B., \& Owe J.F. (2015). Myasthenia gravis and risks for comorbidity. European Journal of Neurology, 22(1), 17-23. https://doi.org/10.1111/ENE.12599

Jaretzki, A., Barohn, R. J., Ernstoff, R. M., Kaminski, H. J., Keesey, J. C., Penn, A. S., \& Sanders, D. B. (2000). Myasthenia gravis: recommendations for clinical research standards. Task Force of the Medical Scientific Advisory Board of the Myasthenia Gravis Foundation of America. Neurology, 55(1), 16-23. https://doi.org/10.1212/WNL.55.1.16

Kupersmith, M. J., Latkany, R., \& Homel, P. (2003). Development of generalized disease at 2 years in patients with ocular myasthenia gravis. Archives of Neurology, 60(2), 243-248. https://doi.org/10.1001/ARCHNEUR.60.2.243 
Lavrnić, D., Jarebinski, M., Rakočević-Stojanović, V., Stević, Z., Lavrnić, S., Pavlović, S., Trikić, R., Tripković, I., Nešković, V., \& Apostolski, S. (1999). Epidemiological and clinical characteristics of myasthenia gravis in Belgrade, Yugoslavia (19831992). Acta Neurologica Scandinavica, 100(3), 168-174. https://doi.org/10.1111/J.1600-0404.1999.TB00733.X

Lee, H. S., Lee, H. S., Shin, H. Y., Choi, Y. C., \& Kim, S. M. (2016). The Epidemiology of Myasthenia Gravis in Korea. Yonsei Medical Journal, 57(2), 419-425. https://doi.org/10.3349/YMJ.2016.57.2.419

Lee, I., Kaminski, H. J., Xin, H., \& Cutter, G. (2018). Gender and quality of life in myasthenia gravis patients from the myasthenia gravis foundation of America registry. Muscle \& Nerve, 58(1), 90-98. https://doi.org/10.1002/MUS.26104

Leeamornsiri, S., Chirapapaisan, N., \& Chuenkongkaew, W. (2011). Clinical profiles of thai patients with ocular myasthenia gravis in siriraj hospital. Journal of the Medical Association of Thailand, 94(9), 1117-1121.

Mantegazza, R., Baggi, F., Antozzi, C., Confalonieri, P., Morandi, L., Bernasconi, P., Andreetta, F., Simoncini, O., Campanella, A., Beghi, E., \& Cornelio, F. (2003). Myasthenia gravis (MG): epidemiological data and prognostic factors. Annals of the New York Academy of Sciences, 998, 413-423. https://doi.org/10.1196/ANNALS.1254.054

Matsuda, M., Dohi-lijima, N., Nakamura, A., Sekijima, Y., Morita, H., Matsuzawa, S., Sato, S. I., Yahikozawa, H., Tabata, K. I., Yanagawa, S., \& Ikeda, S. I. (2005). Increase in incidence of elderly-onset patients with myasthenia gravis in Nagano Prefecture, Japan. Internal Medicine, 44(6), 572-577. https://doi.org/10.2169/INTERNALMEDICINE.44.572

Matsui, N., Nakane, S., Nakagawa, Y., Kondo, K., Mitsui, T., Matsumoto, T., Arisawa, K., \& Kaji, R. (2009). Increasing incidence of elderly onset patients with myasthenia gravis in a local area of Japan. Journal of Neurology, Neurosurgery, and Psychiatry, 80(10), 1168-1171. https://doi.org/10.1136/JNNP.2008.152637

Murai, H., Yamashita, N., Watanabe, M., Nomura, Y., Motomura, M., Yoshikawa, H., Nakamura, Y., Kawaguchi, N., Onodera, H., Araga, S., Isobe, S., Nagai, M., \& Kira, J. (2011). Characteristics of myasthenia gravis according to onset-age: Japanese nationwide survey. Journal of the Neurological Sciences, 305(1-2), 97-102. https://doi.org/10.1016/J.JNS.2011.03.004

Pakzad Z., Aziz T., \& Oger J. (2011). Increasing incidence of myasthenia gravis among elderly in British Columbia, Canada. Neurology, 76(17), 1526-1528. https://doi.org/10.1212/WNL.0B013E318217E735

Poulas, K., Tsibri, E., Kokla, A., Papanastasiou, D., Tsouloufis, T., Marinou, M., Tsantili, P., Papapetropoulos, T., \& Tzartos, S. (2001). Epidemiology of seropositive myasthenia gravis in Greece. Journal of Neurology, Neurosurgery, and Psychiatry, 71(3), 352. https://doi.org/10.1136/JNNP.71.3.352

Oparah, S.K., \& Ibanga, A.A. (2020). Myasthenia Gravis at Presentation: A 14 Year Instituti 3(3), 22-28 onal Review of a Rare Disorder in Calabar, Southern Nigeria. Asian Journal of Medical Principles and Clinical Practice, 3(3), 22-28 https://www.journalajmpcp.com/index.php/AJMPCP/article/view/30120

Singhal, Bhatia, N. S., Umesh, T., \& Menon, S. (2008). Myasthenia gravis: A study from India. Neurology India, $56(3), 352$. https://doi.org/10.4103/0028-3886.43455

Turner, C. (2007). A review of myasthenia gravis: Pathogenesis, clinical features and treatment. Current Anaesthesia and Critical Care, 18(1), 15-23. https://doi.org/10.1016/J.CACC.2007.01.006

Vincent, A. (2008). Autoimmune disorders of the neuromuscular junction. Neurology India, 56(3), 305. https://doi.org/10.4103/0028-3886.43449

Wing, Lok., Mrcp, A. U., Das, A., Fams, A., Tjia, H. T., \& Fams, M. (2003). Myasthenia gravis in Singapore. Neurology Asia, 8 , 35-40. http://www.neurology-asia.org/articles/20031 035.pdf

Yu, Y. L., Hawkins, B. R., Ip, M. S., Wong, V., \& Woo, E. (1992). Myasthenia gravis in Hong Kong Chinese. 1. Epidemiology and adult disease. Acta Neurologica Scandinavica, 86(2), 113-119. https://doi.org/10.1111/J.1600-0404.1992.TB05050.X 